\title{
Reasons for not initiating osteoporosis therapy among a managed care population
}

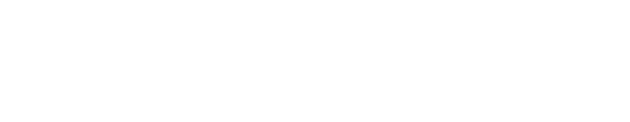

Jingbo $\mathrm{Yu}^{\prime}$

Susan K Brenneman ${ }^{2}$

Vasilisa Sazonov'

Ankita Modi'

'Center for Observational and Real-World Evidence, Merck \& Co., Inc., Kenilworth, NJ, USA; ${ }^{2}$ Health Economics and Outcomes Research, Optum, Eden Prairie, MN, USA
Correspondence: Ankita Modi Center for Observational and RealWorld Evidence, Merck \& Co., Inc., 2000 Galloping Hill Rd, Kenilworth, NJ 07033, USA

$\mathrm{Tel}+\mathrm{I} 9082364563$

Fax +I 9082364089

Email ankita.modi@merck.com
Background: Many women with osteoporosis do not initiate osteoporosis treatment.

Objective: To examine patients' reasons for not initiating osteoporosis treatment among women with osteoporosis.

Methods: Survey recipients were identified from a national US claims database and included women $\geq 55$ years with an osteoporosis diagnosis from January 1, 2010 to March 31, 2012 as defined by: 1) osteoporosis diagnosis coupled with bone mineral density test within 183 days of diagnosis and/or 2) osteoporosis-related fracture. Eligibility required no claims for osteoporosis medication 1) at least 12 months and up to 5 years prior to osteoporosis diagnosis and 2) at least 6 months after osteoporosis diagnosis. Continuous enrollment for 18 months (6 months pre-osteoporosis and 12 months post-osteoporosis diagnosis) was also required. A total of 2,000 patients with the most recent osteoporosis diagnosis were mailed a survey. Respondents reporting that they did not initiate physician-recommended osteoporosis medication, after either their physician told them they had osteoporosis or they experienced a fracture since age 45 years, were asked for reasons why they did not initiate treatment.

Results: There were 430 patients who returned a complete survey; mean age was $61 \%$ and $21.6 \%$ had a fracture. A total of 197 (45.8\%) patients reported their physician diagnosed osteoporosis and 117 (59.3\%) of those were recommended osteoporosis medication; 44 of the 117 patients (37.6\%) did not initiate recommended osteoporosis medication by the time of survey. The primary reasons for not initiating osteoporosis medication were concern over side effects (77.3\%), medication costs (34.1\%), and pre-existing gastrointestinal concerns (25.0\%).

Conclusion: Among respondents, $41 \%$ of patients whose physician diagnosed osteoporosis were not recommended osteoporosis treatment and $38 \%$ of patients who were recommended osteoporosis treatment did not initiate treatment within approximately 2 years of diagnosis. Concerns with side effects of osteoporosis treatment, medication costs, and pre-existing gastrointestinal concerns were the most common reasons for not initiating recommended treatment. Keywords: bisphosphonate, primary nonadherence, patient survey, treatment initiation

\section{Introduction}

Osteoporotic fractures impose a significant health and economic burden in the US. The direct costs of osteoporotic fracture were estimated at US\$19B in 2005, rising to $\$ 25 \mathrm{~B}$ in 2025 , largely as a consequence of an aging population with an inherently higher risk of fracture. ${ }^{1}$ The indirect costs of osteoporotic fractures are also substantial, including significant decrements in quality of life $\mathrm{e}^{2,3}$ and excess mortality. ${ }^{4}$

The US Food and Drug Administration have approved several treatments for osteoporosis, including bisphosphonates (alendronate, ibandronate, risedronate, zoledronic acid) and non-bisphosphonates (calcitonin, denosumab, raloxifene, teriparatide). The National Osteoporosis Foundation recommends bone mineral density (BMD) testing be considered for all women aged 65 years and older irrespective of 
fracture risk and post-menopausal women 50 years and older with clinical risk factors for fracture. ${ }^{5}$ Pharmacologic treatment should be considered for postmenopausal women aged 50 years and older with a hip or vertebral fracture, BMD T-score $\leq-2.5$, or low bone mass coupled with an elevated fracture risk according to the FRAX ${ }^{\circledR}$ model..$^{5}$ An estimated $30 \%$ of US women aged 50 years and older in the US met the National Osteoporosis Foundation criteria for pharmacologic management of osteoporosis during 2005-2008. ${ }^{6}$

Despite the availability of multiple treatment options, the clinical management of osteoporosis remains challenging. In recent US studies, less than $20 \%$ of women who had sustained their first fragility fracture were being treated within the first year after the fracture ${ }^{7}$ and only $38 \%-58 \%$ of women who reported an osteoporosis diagnosis or high risk of fracture were receiving treatment. ${ }^{8-10}$

Treatment initiation is an essential first step in the management of osteoporosis, but the rates of treatment initiation and the patient-specific rationale for not initiating treatment, despite an osteoporosis diagnosis, have received less scrutiny than adherence and persistence among patients who do initiate treatment. A US internet survey of patients with five common chronic conditions found that the rate of not filling a new prescription provided in the last year for an osteoporosis drug was approximately two- to seven-fold higher than the rate of nonfulfillment of prescriptions for other chronic conditions; medication costs and side effects tied as the top reasons for nonfulfillment of osteoporosis prescriptions. ${ }^{11}$ Approximately $30 \%$ of women in California did not fill a new prescription for bisphosphonates within 60 days of the order. ${ }^{12}$ In a study of patients in a Massachusetts' health plan, $43 \%$ of patients with an osteoporosis diagnosis did not initiate osteoporosis treatment within 3 months of their diagnosis and were more likely to report distrust of medications and concern over side effects than patients who did initiate therapy. ${ }^{13}$

While these studies provide important insight into the rate of undertreatment and reasons some patients do not fill their prescriptions for osteoporosis drugs, limitations include a lack of evidence of an osteoporosis diagnosis, ${ }^{12}$ treatment naïve status, ${ }^{11}$ or physician recommendation to initiate treatment. ${ }^{13}$ Evidence of an osteoporosis diagnosis is an important consideration in discerning patient rationale for not initiating physician-recommended therapy because most approved osteoporosis treatments may be prescribed for either prevention or treatment of osteoporosis; patients who reject preventative treatment may have different rationale for doing so, such as lower perceived risk of fracture, than patients prescribed therapy to treat an existing condition. ${ }^{9}$
Patients who initiate treatment and subsequently discontinue may have different reasons for not resuming therapy - such as direct experience with side effects ${ }^{14}$ - than treatmentnaïve patients who elect not to initiate treatment. Similarly, evidence that a physician recommended treatment for a patient diagnosed with osteoporosis is required to distinguish the patient-specific rationale for not initiating treatment from the physician decision not to recommend treatment.

The objective of our study was to understand reasons why osteoporotic patients do not initiate treatment, by surveying a managed care population in the US.

\section{Methods \\ Design and data source}

We conducted a cross-sectional mail survey of women naïve to osteoporosis medications with claims-based evidence of recent osteoporosis-related medical services. Candidates for the survey were identified from the Optum Research Database, a health care claims database affiliated with a national health plan, which includes enrollment information and medical and pharmacy claims. Medical claims include International Classification of Diseases, Ninth Revision, Clinical Modification (ICD-9-CM) diagnosis and procedure codes, Current Procedural Terminology codes, Healthcare Common Procedure Coding System codes, and provider specialty codes. Pharmacy claims contain outpatient prescription pharmacy services, including drug name, dosage form, drug strength, and fill date. The study protocol received approval from a central Institutional Review Board, and the study design was approved by the health plan's Research Review Board.

\section{Patient identification}

The claims database was used to identify untreated, osteoporotic patients eligible for the survey. To be included in the study, patients must have had evidence of osteoporosis during the identification period (January 1, 2010-March 31, 2012) as indicated by the following event(s): 1) a diagnostic code for osteoporosis (ICD-9-CM 733.0x) and evidence of a BMD test (current procedural terminology codes: 77080, $77081,77082,3095 \mathrm{~F}$ ) within 183 days of the claim with a diagnostic code for osteoporosis and/or 2) claims evidence of an osteoporosis-related fracture. The index date was the most recent date of the osteoporosis diagnosis or fracture. Patients were also required to be untreated, defined as no claims for osteoporosis-specific medications, including bisphosphonates (alendronate, ibandronate risedronate, zoledronic acid) and non-bisphosphonates (calcitonin, denosumab, raloxifene, teriparatide) for 1) at least 12 months and up to 5 years 
pre-index and 2) during 6 months post-index. Inclusion also required that patients be women aged 55 and older (as of the index date) and have continuous enrollment with medical and pharmacy benefits in a commercial plan during the 12-month pre-index (baseline) and the 6-month post-index (follow-up) periods. Patients were excluded if they had evidence of any of the following conditions during baseline or follow-up: dementia, Alzheimer's disease, or mild cognitive disorder (ICD-9-DM codes: 290.xx, 291.2, 292.82, 294.1x, 294.8, 331.0-331.1x, 331.7-331.82, 331.83); Paget's disease (ICD-9-DM 731.0); malignant neoplasms (ICD-9-DM codes: 140.xx-171.xx, 173.xx-208.xx, 230.xx-239.xx); Parkinson's disease (ICD-9-DM code: 332.0, 332.1); or Huntington's disease (ICD-9-DM code: 333.4). Patients with evidence of estrogen use during the baseline period were also excluded.

\section{Survey eligibility and issuance}

Among the patients who met the claims-based criteria for evidence of osteoporosis (patients with an osteoporosis diagnosis or fracture, all without treatment), 2,000 patients with the most recent index dates were selected to receive a survey. The most recent index date was used as a survey selection criterion to minimize the period between osteoporosis diagnosis and survey completion to lessen the potential for patient recall bias or subsequent osteoporosis treatment initiation. In addition, the proportion of all patients who met the claims-based evidence of osteoporosis on the basis of an osteoporosis diagnosis, fracture, or both were determined. A sample of 2,000 patients who received a survey was selected to match these proportions. The initial survey was mailed on May 31, 2013 and included a pre-paid \$10 incentive; a postcard reminder to complete the survey was sent 2 weeks later. Four weeks after the initial mailing, nonrespondents received a second survey, excluding the pre-paid incentive. Surveys were collected for 8 weeks following the initial mailing. Patients who completed the survey and signed and returned informed consent and health release forms were eligible to be included in the analytic sample.

\section{Measures}

Demographic and clinical characteristics of patients were determined from claims data, and these included age (as of the index date), the time from their index date to the initial survey mailing, US Census region, and the type of event that qualified as evidence of osteoporosis (ie, osteoporosis diagnosis, osteoporosis-related fracture). Baseline characteristics included the Deyo-Charlson comorbidity score, ${ }^{15}$ presence or absence of a closed fracture, and total health care costs. Costs were computed from the sum of health plan- and patient-paid amounts and represented claims for all medical services (ambulatory, emergency room, inpatient, and other) and pharmacy claims. Costs were adjusted using the annual medical care component of the Consumer Price Index to reflect inflation between 2010 and 2011. ${ }^{16}$

The survey contained questions related to patient reasons for not initiating treatment and patient knowledge and beliefs about osteoporosis. Only patients who had evidence of osteoporosis and did not initiate physician-recommended osteoporosis treatment, as indicated by their response to the following three screening questions, were asked to provide reasons for not initiating osteoporotic therapy and to complete the rest of the questionnaire:

1. "Has your physician or health care provider ever told you that you have osteoporosis, OR have you had a fracture since you were age 45?" (required response: yes).

2. "After your physician told you that you have osteoporosis or you experienced a fracture, did your physician recommend treatment with medication (excluding calcium and vitamin D)?" (required response: yes).

3. "Since you received osteoporosis diagnosis or had a fracture, have you ever taken any medication for osteoporosis?" (required response: no).

The survey contained 16 possible reasons for not taking physician-recommended osteoporosis medication (excluding vitamin D and/or calcium), and these were grouped into four categories representing cost of medication, convenience of taking medication, method of medication administration, and health-related concerns, which included seven stomach or digestion problems and an option to write in other stomach or digestion problems not listed on the survey. Respondents could select more than one reason for not taking osteoporosis medication. Knowledge and beliefs about osteoporosis were evaluated by seven statements related to fractures, treatment, and management, each with five response categories: strongly agree, agree, neutral, disagree, and strongly disagree. Patients rated the importance of 16 treatment-related factors in their decision to take recommended medication (osteoporosis or other medication) by responding that the factor was not at all important, moderately important, or very important. Patients also reported the osteoporosis medication and management that their physician recommended and their use of over-thecounter calcium and/or vitamin D supplements.

\section{Statistical analyses}

The sample size required to achieve a $95 \%$ confidence interval of \pm 0.05 based on proportion outcomes ranging from 
0.1 to 0.9 was estimated. The largest sample size in the range was 385 respondents, and we estimated that 2,000 patients would need to be contacted to achieve the desired sample of respondents. The patient characteristics were compared within three sets of survey respondents defined as follows: 1) patients who reported that their physician told them they had osteoporosis or who reported a fracture since age 45 years vs those who did not; 2) among the subset of patients who reported that their physician told them they had osteoporosis (or reported a fracture since age 45), those patients whose physician recommended osteoporosis treatment vs those whose physician did not; and (3) among those patients whose physician told them they had osteoporosis and recommended osteoporosis treatment, those who initiated osteoporosis treatment vs those who did not. The differences between groups were assessed by two-sided $t$-test (continuous variables) and chi-square test (categorical variables).

\section{Results}

\section{Patient selection and survey response}

There were 102,404 women aged 55 years or older with evidence of osteoporosis during the identification period, and 18,502 (18.1\%) met the claims-based criteria for inclusion in the survey (Figure 1). The predominant reasons for exclusion were claims for an osteoporosis medication during baseline or follow-up $(n=53,201,52.0 \%)$ and lack of continuous enrollment in the health plan for 12 months pre-index and 6 months post-index $(n=17,813,17.4 \%)$. Of the 2,000 surveys mailed, 491 (24.6\% response rate) were returned and $430(87.6 \%)$ had evaluable information. The characteristics of survey respondents $(n=491)$ and non-respondents $(n=1,509)$ were similar for age distribution, geographic region, and type of osteoporosis evidence with the exception that a slightly higher proportion of non-respondents vs respondents were between ages 55 and 64 years $(85.7 \%$ vs $81.9 \%, P=0.041)$, had a fracture as evidence of osteoporosis $(25.5 \%$ vs $20.4 \%, P=0.021)$, and resided in the southern region of the US (55.6\% vs $49.5 \%$, $P=0.018$ ) (data not shown). The distribution of the type of evidence for osteoporosis for the 491 survey respondents vs the 18,502 patients who met the claims-based survey eligibility criteria was osteoporosis diagnosis coupled with BMD test, $75.4 \%$ vs $74.4 \%$; fracture, $20.4 \%$ vs $23.9 \%$; and both fracture and osteoporosis diagnosis, $4.3 \%$ vs $1.7 \%$.

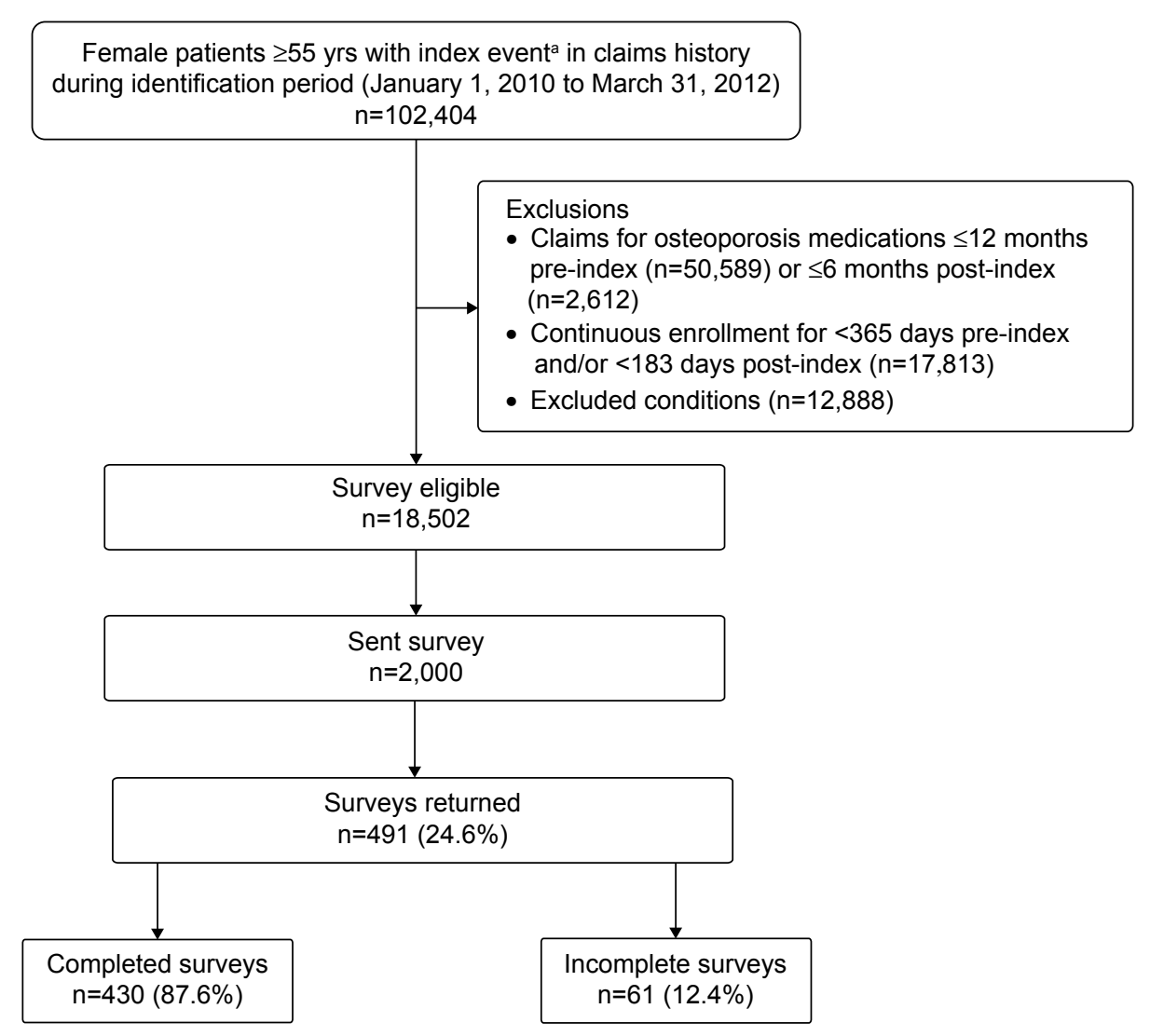

Figure I Patient selection and survey response.

Notes: a Diagnosis of osteoporosis and evidence of bone mineral density test within 183 days of diagnosis or evidence of osteoporosis-related fracture during identification period. Index date is the date of osteoporosis diagnosis or osteoporosis-related fracture (whichever was most recent) during the identification period. Abbreviation: yrs, years. 


\section{Survey respondents}

Of the 430 respondents, 233 patients (54.2\%) reported that that they were not told by their physician that they had osteoporosis or had not experienced a fracture since age 45 (Figure 2). The remaining 197 patients reported that their physician told them they had osteoporosis (or they self-reported a fracture since age 45 years), and 80 patients (40.6\%) reported that the physician did not recommend osteoporosis treatment. Of the 117 patients who reported that their physician recommended osteoporosis treatment, 44 patients (37.6\%) chose not to take osteoporosis medication. Overall, 124 of the 197 patients (62.9\%) who reported that they were told by their physician they had osteoporosis (or selfreported a fracture since age 45 years) were not treated with osteoporosis medications either because they reported that their physician did not recommend treatment $(n=80)$ or they reported that they did not initiate treatment $(n=44)$.

\section{Baseline characteristics}

For all patients, mean age was 61 years, $83.7 \%$ were 55-64 years old, and $21.6 \%$ had an osteoporotic fracture as evidence of osteoporosis (Table 1). Mean age, comorbidity score, health care costs were similar between groups within each of the three sets of patients. A higher proportion of patients who reported that their physician did not recommend osteoporosis treatment had an osteoporosis-related fracture as evidence of osteoporosis ( $37.5 \%$ vs $13.7 \%, P<0.001)$ and a baseline osteoporosis-related fracture $(37.5 \%$ vs $16.2 \%$, $P<0.001$ ), compared with patients who reported that their physician did recommend osteoporosis treatment. Across the three sets, the mean time from index date to survey mailing ranged from 654 days to 770 days and was longer among patients who reported they were not told by their physician that they had osteoporosis than among patients who were told (770 days vs 678 days, $P<0.001$ ).

\section{Survey results}

There were 44 patients who reported that they did not initiate osteoporosis treatment after being told by their physician they had osteoporosis (or sustained a fracture since age 45) and their physician recommended osteoporosis treatment. The primary reason for not initiating treatment prescribed for osteoporosis was health related, with $77.3 \%$ of patients citing concern over side effects (Table 2). Twenty-five percent $(n=11)$ of patients also cited pre-existing stomach or digestion conditions as a reason for not initiating treatment, primarily acid reflux (72.7\%), heart burn (54.6\%), upper abdominal pain (54.6\%), and nausea/vomiting (27.3\%). The second most common reason for failure to initiate prescribed treatment was cost-related prescription: $34.1 \%$ cited the cost of medication and $18.2 \%$ indicated their health insurance did not cover the prescribed medication.

Patient ranking of the importance of factors in their decision to use a recommended treatment is shown in Figure 3. The ranking was for any recommended treatment medication (eg, not specific to osteoporosis), and all 16 factors were ranked at least moderately important by the majority of patients. More than $95 \%$ of patients ranked the kinds of treatment side effects $(97.7 \%)$ and likelihood of treatment side effects $(95.5 \%)$ as very important factors. Other factors ranked very important by a majority of patients included whether the treatment would limit daily activities (86.4\%), the patient heard negative things about the treatment $(72.1 \%)$, the health insurance paid part of treatment cost $(70.5 \%)$, the

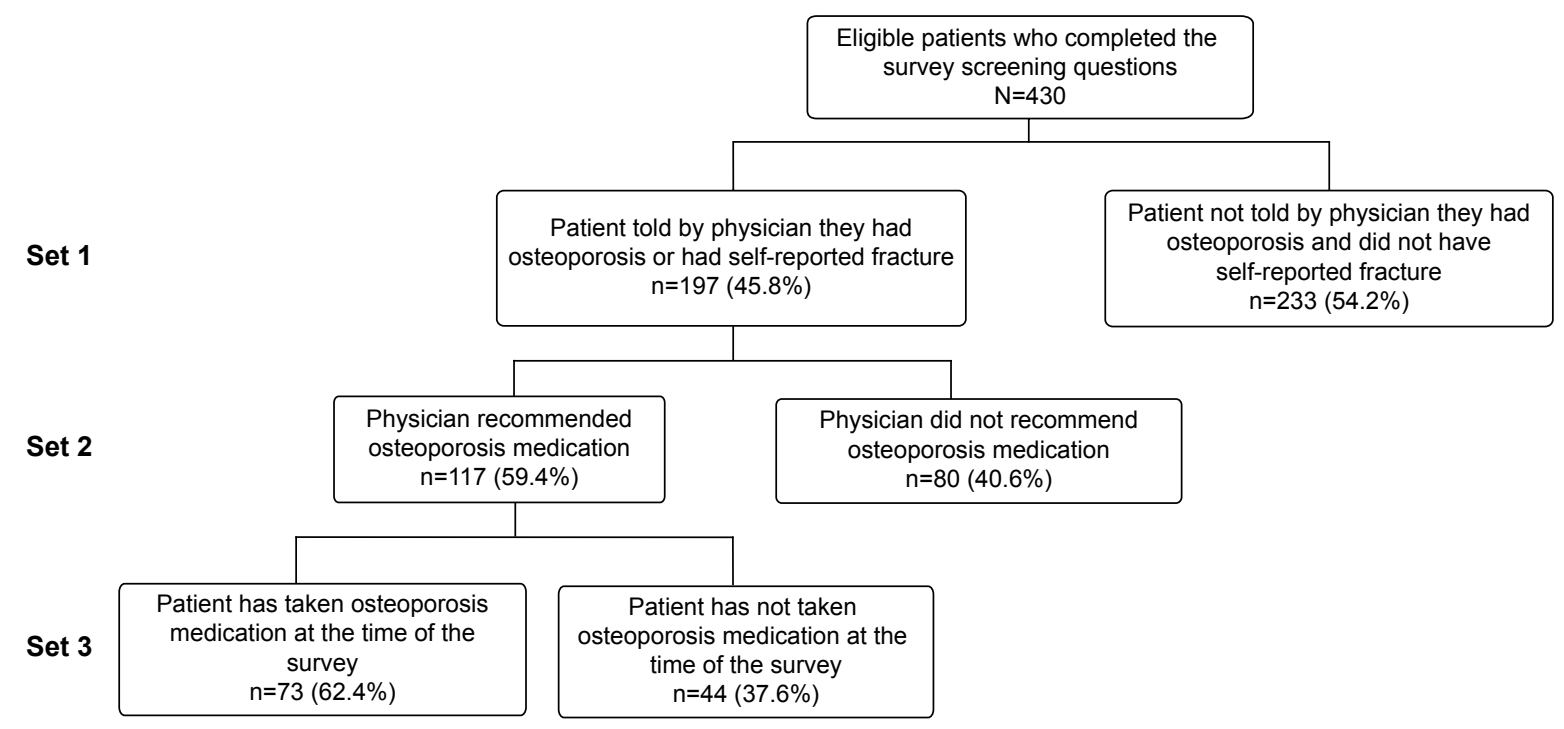

Figure 2 Sets of patients derived from survey screening questions. 


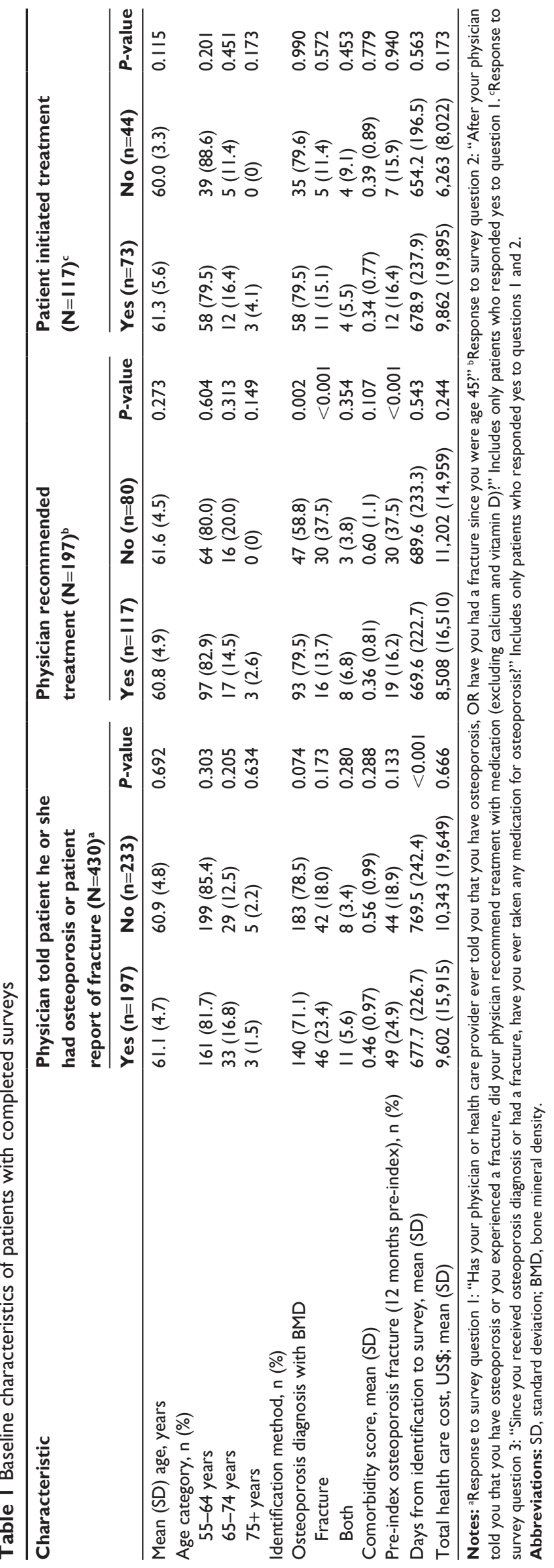

Table 2 Reasons for not initiating treatment among patients for whom physician recommended pharmacological osteoporosis treatment

\begin{tabular}{ll}
\hline Reasons for not initiating treatment & Total $(\mathbf{N}=\mathbf{4 4})$ \\
\cline { 2 - 2 } & $\mathbf{n}(\%)$ \\
\hline Cost & $15(34.1)$ \\
Cost of medication & $8(I 8.2)$ \\
Health insurance does not cover the medication & \\
Convenience & $6(13.6)$ \\
Inconvenient to take the medication & $5(I I .4)$ \\
Taking too many medications & $2(4.6)$ \\
Travel to physician's office for medication & \\
Method & $7(15.9)$ \\
Do not like injections & $3(6.8)$ \\
No medications recommended & $0(0)$ \\
Unable to sit upright for at least 30 minutes & \\
to take the medication as directed & \\
Health related & $34(77.3)$ \\
Concerns of side effects & $8(I 8.2)$ \\
Worry about interfering with other medications & $8(I 8.2)$ \\
Other health conditions that are more troubling & $3(6.8)$ \\
Kidney problems & $1 \mathrm{II}(25.0)$ \\
Stomach or digestion problems & $3(6.8)$ \\
Medication does not make any difference & $6(13.6)$ \\
Osteoporosis does not affect health & $4(9.1)$ \\
Other &
\end{tabular}

Note: aStomach or digestion problems reported were acid reflux $(n=8,72.7 \%)$, heart burn $(n=6,54.6 \%)$, upper abdominal pain $(n=6,54.6 \%)$, nausea/vomiting $(n=3$, $27.3 \%)$, bloating $(n=2,18.2 \%)$, other problem $(n=2,18.2 \%)$, swallowing problems $(n=1,9.1 \%)$, stomach bypass surgery $(n=1,9.1 \%)$, and ulcers $(n=1,9.1 \%)$.

treatment could completely cure the condition (65.9\%), and the treatment could be taken at home (63.6\%).

Patient knowledge and beliefs about osteoporosis are shown in Table 3. Although 95.5\% of patients had knowledge of osteoporosis before their diagnosis, only $34.1 \%$ responded that they had a discussion with their physician about osteoporosis prior to diagnosis. More than $90 \%$ of patients agreed or strongly agreed that osteoporosis can cause bones to become weak (93.2\%) and break easily (95.5\%) and $84.1 \%$ agreed/strongly agreed that calcium and vitamin D are important for healthy bones. Most patients (86.4\%) disagreed or strongly disagreed that they should not exercise because they might break a bone. A lesser percentage (65.9\%) disagreed or strongly disagreed with the statement that nothing can be done to treat osteoporosis and that they do not need to take osteoporosis medication because they do not feel sick with osteoporosis (58.2\%).

Oral bisphosphonates were the predominant treatment recommended by physicians with 35 of the 44 patients reporting that their physician recommended alendronate, ibandronate, or risedronate (Table 4). Most patients indicated that their physician also recommended calcium supplements (84.1\%), vitamin D supplements $(81.8 \%)$, and exercise 


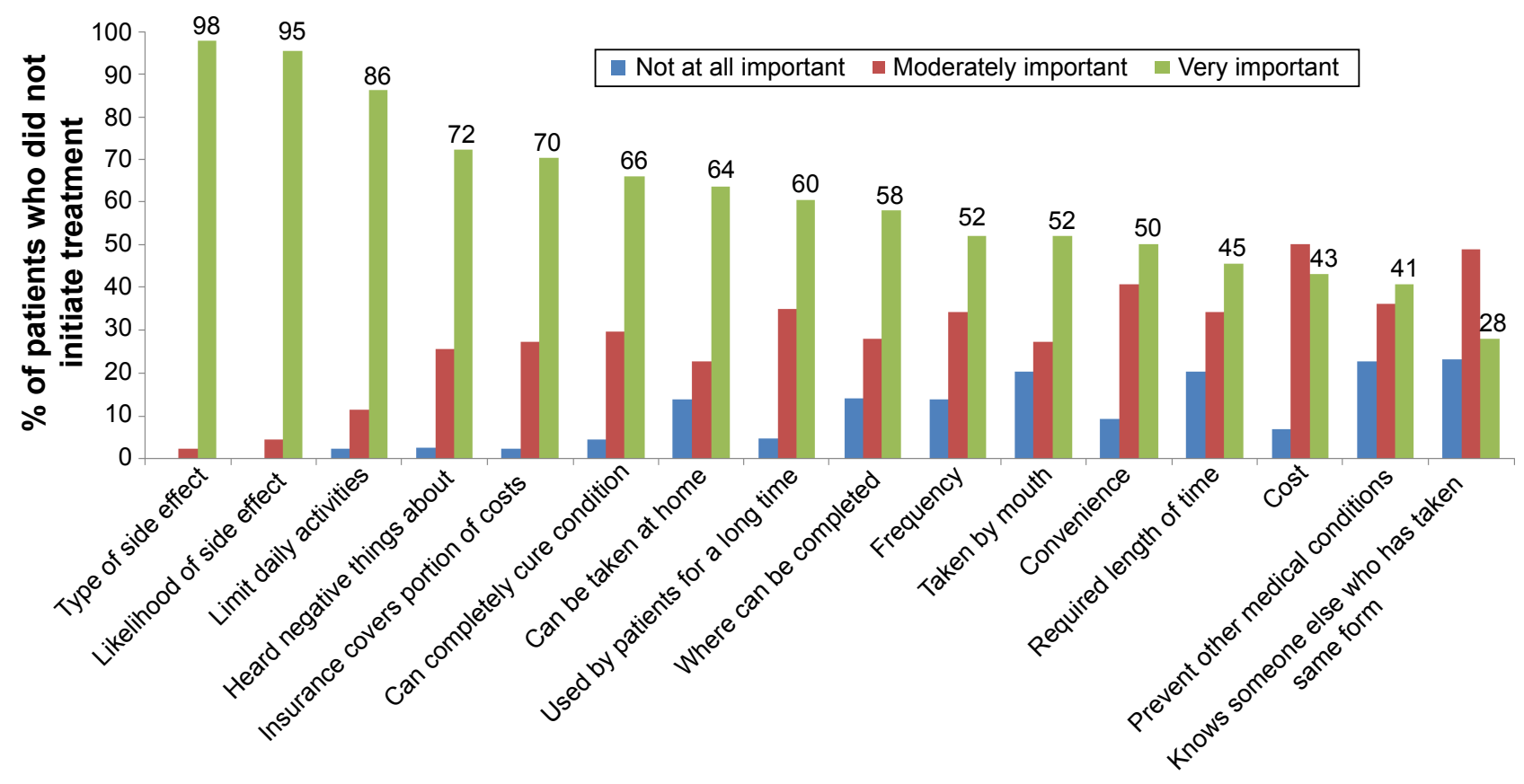

Figure 3 Importance of treatment-related factors in choice of whether to use a recommended treatment among 44 patients for whom physician recommended osteoporosis treatment but who did not initiate osteoporosis treatment.

Note: $\mathrm{N}=43$ responses for these survey items: where can be completed, heard negative things about, knows someone else who has taken same form of treatment, and used by patients for a long time.

(70.5\%), and $81.4 \%$ of patients reported taking over-thecounter calcium and vitamin D supplements.

\section{Discussion}

Our study reveals substantial undertreatment of women diagnosed with osteoporosis and the patient-specific rationale for not initiating osteoporosis treatment recommended by their physician. Undertreatment was a function of both the physician not recommending treatment and the patient choosing not to initiate treatment: $41 \%$ of patients reported that their physician told them they had osteoporosis but did not recommend treatment and $38 \%$ of patients did not initiate physician recommended treatment within approximately 2 years of their diagnosis and/or fracture. Among patients who did not initiate recommended treatment, the predominant reason for not initiating treatment was concern over side effects (77\%), followed by the cost of medication (34\%), and pre-existing stomach or digestion problems (25\%).

Previous US studies indicate that $41 \%-64 \%$ of women with either a claims-based or self-reported diagnosis of

Table 3 Patient knowledge and beliefs about osteoporosis among patients for whom physician recommended osteoporosis treatment but who did not initiate osteoporosis treatment

\begin{tabular}{|c|c|c|c|c|}
\hline \multirow[t]{2}{*}{ Survey item } & \multicolumn{4}{|c|}{ Survey item response $(\mathrm{N}=44), \mathrm{n}(\%)$} \\
\hline & Yes & Agree $^{a}$ & Neutral & Disagree $^{b}$ \\
\hline Knowledge of osteoporosis prior to diagnosis & $42(95.5)$ & - & - & - \\
\hline Discussion with physician about osteoporosis prior to diagnosis & $15(34.1)$ & - & - & - \\
\hline Having osteoporosis is of great concern to me & - & $30(68.2)$ & $9(20.5)$ & $5(11.4)$ \\
\hline Osteoporosis causes bones to become weak & - & $4 \mid(93.2)$ & I (2.3) & $2(4.6)$ \\
\hline When someone has osteoporosis, it is easy to break a bone & - & $42(95.5)$ & $2(4.6)$ & $0(0)$ \\
\hline There is nothing that can be done to treat osteoporosis & - & $2(4.6)$ & $13(29.6)$ & $29(65.9)$ \\
\hline If I have osteoporosis, I should not exercise because I might break a bone & - & $3(6.8)$ & $3(6.8)$ & $38(86.4)$ \\
\hline Since I do not feel sick with osteoporosis, I do not need to take medication ${ }^{c}$ & - & $7(16.3)$ & II (25.6) & $25(58.2)$ \\
\hline Calcium and vitamin D are important for healthy bones & - & $37(84.1)$ & $4(9.1)$ & $3(6.8)$ \\
\hline
\end{tabular}

Notes: ancludes the response categories of agree and strongly agree. 'Includes the response categories of disagree and strongly disagree. In all, 43 patients responded to this survey item. "-" Indicates that this response was not an option for that survey item. 
Table 4 Physician recommended osteoporosis treatment and management, and patient use of over-the-counter calcium and vitamin $\mathrm{D}$ products among patients for whom physician recommended osteoporosis treatment but who did not initiate osteoporosis treatment

\begin{tabular}{|c|c|}
\hline Survey item & $\begin{array}{l}\text { Patients who did not initiate } \\
\text { treatment }(\mathrm{N}=44),{ }^{\mathrm{a}} \mathrm{n}(\%)\end{array}$ \\
\hline \multicolumn{2}{|l|}{ Physician recommended medications ${ }^{\mathrm{b}}$} \\
\hline \multicolumn{2}{|l|}{ Bisphosphonate } \\
\hline Fosamax (alendronate) & $16(36.4)$ \\
\hline Boniva (ibandronate) & $12(27.3)$ \\
\hline Actonel (risedronate) & $7(15.9)$ \\
\hline Reclast (zoledronic acid) & $3(6.8)$ \\
\hline \multicolumn{2}{|l|}{ Non-bisphosphonate } \\
\hline Forteo (teriparatide) & $4(9.1)$ \\
\hline Estrogen or hormone therapy & $3(6.8)$ \\
\hline Prolia (denosumab) & $2(4.6)$ \\
\hline Evista (raloxifene) & $\mathrm{I}(2.3)$ \\
\hline Miacalcin (calcitonin) & $0(0)$ \\
\hline \multicolumn{2}{|l|}{ Physician recommended management } \\
\hline Calcium supplement & $37(84.1)$ \\
\hline Vitamin D supplement & $36(81.8)$ \\
\hline Exercise & $31(70.5)$ \\
\hline No recommendations & $4(9.1)$ \\
\hline \multicolumn{2}{|c|}{ Over-the-counter supplements taken by patient for osteoporosis } \\
\hline Calcium and vitamin D & $35(81.4)$ \\
\hline Only vitamin D & $3(7.0)$ \\
\hline Only calcium & $2(4.7)$ \\
\hline No calcium or vitamin $D$ & $3(7.0)$ \\
\hline
\end{tabular}

Notes: ${ }^{a}$ Due to non-responses on the survey, $\mathrm{N}$ is less than 44 for some categories. bSome patients reported more than one physician recommended medication.

osteoporosis were not receiving recommended osteoporosis treatment. ${ }^{7,8,10,17}$ Our results indicate a limitation in the use of administrative claims data for identifying an osteoporosis diagnosis. Based on claims evidence, 430 patients had an event that served as the basis of osteoporosis diagnosis; yet only 197 of these patients (46\%) reported that their physician diagnosed osteoporosis or that they had experienced a fracture. The event for $75 \%$ of the 430 patients identified through the claims data was an osteoporosis diagnostic code coupled with a recent BMD test. It is possible that a considerable portion of these events represented screening for osteoporosis and the BMD test results did not support a diagnosis of osteoporosis. Thus, claims-based studies that use a diagnostic code for osteoporosis in conjunction with a BMD test to identify cases of osteoporosis may overestimate the number of patients who have osteoporosis unless the definition of osteoporosis also requires a pharmacy claim for an osteoporosis treatment. Because our study focused on undertreatment of patients who were also treatment naïve, we excluded patients with a pharmacy claim for osteoporosis treatment.
Despite their physician's recommendation to initiate osteoporosis treatment, $38 \%$ of these patients did not initiate treatment. These results are consistent with a study of primary nonadherence in California: $30 \%$ of women newly prescribed bisphosphonates did not fill the prescriptions within 60 days. ${ }^{12}$ Concern over side effects was by far the most common reason - cited by $77 \%$ of our patients - for not initiating osteoporosis treatment. The likelihood and type of side effects were also ranked as very important factors in making the decision to use recommended medications by more than $95 \%$ of patients who did not initiate treatment. A previous study noted a higher degree of concern over side effects among patients who do not initiate treatment compared with patients who do initiate treatment. ${ }^{13}$ Further, side effects and distrust of medications, in general, have been reported as the most common reasons why osteoporotic women rejected their physician's recommendation for bisphosphonate treatment. ${ }^{18}$ Oral bisphosphonates were by far the most frequently recommended treatment in our study. In a discrete choice experiment of osteoporosis medication attributes, dislike of gastrointestinal disorders was ranked higher than other common side effects ${ }^{19}$ and $25 \%$ of patients in our study cited stomach or digestion problems as a rational for not initiating recommended treatment. Our results coupled with previous studies suggest that patient concern over side effects and gastrointestinal intolerance in particular may pose a significant barrier to initiating treatment.

Cost of medication was the second most common reason for not initiating treatment, cited by $34 \%$ of patients, and the contribution of health insurance to medication costs was considered very important by $71 \%$ of patients. All patients in our study had some form of prescription coverage, which may explain the lesser emphasis on medication cost and greater focus on the contribution of insurance to medication costs.

Patient beliefs about osteoporosis and osteoporosis medication also likely inform the patient decision to take recommended osteoporosis medication. While $96 \%$ of patients who did not initiate osteoporosis treatment agreed that osteoporosis makes it easy to break a bone, only $68 \%$ agreed that having osteoporosis was a great concern to them and only $58 \%$ disagreed with the statement that they did not need to take treatment because they do not feel sick with osteoporosis. Our results parallel a previous survey of osteoporotic women - more than $80 \%$ of treatment initiators and non-initiators agreed that osteoporosis was a very serious disease - but the authors suggest that medication beliefs, 
including both efficacy and side effects, better discriminated between treatment initiators and non-initiators than disease severity beliefs. ${ }^{13}$

Only $34 \%$ of patients who did not initiate treatment in our study reported having a discussion with their physician about osteoporosis prior to their diagnosis; yet $96 \%$ of noninitiators reported knowledge of osteoporosis before their diagnosis, suggesting that their beliefs about osteoporosis were influenced by other sources. For example, in interviews with elderly osteoporotic women, some patients discontinued their medication not because they had personal experience with side effects but because they had learned about side effects from the media and other sources. ${ }^{20}$ In a qualitative study of osteoporotic patients who had already sustained a fragility fracture, nearly half found the decision to take osteoporosis medication difficult and used sources other than their physician to evaluate potential risks and benefits of treatment. ${ }^{21}$ Physicians can provide a balanced view of risks and benefits of osteoporosis treatment, but their efforts may be hampered if they are perceived as ineffective in communicating with their patient or if the patient already has firmly established beliefs about osteoporosis and osteoporosis medications. $^{21}$

Patient beliefs and treatment preferences are essential considerations for effective clinical management of osteoporosis. Our results provide insight into the reasons patients choose not to initiate treatment with concern over medication side effects as a predominant factor. Physicians should actively engage patients in treatment discussions, clearly explaining their specific risk factors and providing a balanced view of the risks and benefits of their treatment options. Future research should examine appropriate risk communication tools $\mathrm{s}^{22}$ to improve patient understanding of preventative care measures and treatment of osteoporosis.

\section{Limitations}

Our results are based on a patient survey and claims data, and the results should be considered in this context. The response to the survey was voluntary, and the sample of respondents may be biased toward patients who are more actively engaged in their health. The diagnosis of osteoporosis was based on self-report and not confirmed by medical records or physician contact. Further, the results of BMD scores, which could confirm the presence and severity of osteoporosis, were not available from claims. The sample size of patients not initiating treatment was relatively small, and patients who did initiate treatment were not surveyed as a comparator group. For patients who reported that their physician diagnosed osteoporosis, the rationale for not recommending treatment was not available from claims data or from the patient survey. Finally, our results are limited to a stable, managed care population with prescription drug benefits and may not be applicable to patients with other forms of insurance or those uninsured.

\section{Conclusion}

Based on the patients' reports, $41 \%$ of osteoporotic patients did not receive a recommendation for pharmacologic management of osteoporosis by their physicians. Among patients whose physician did recommend osteoporosis treatment, 38\% did not initiate treatment within an average of 2 years from diagnosis. Patients' concern over side effects of treatment was the predominant reason $(77.3 \%)$ for not initiating physician-recommended treatment, followed by medication cost (34.1\%) and pre-existing gastrointestinal concerns $(25.0 \%)$.

\section{Acknowledgments}

This study was funded by Merck \& Co., Inc. Medical writing support was provided by Sarah Peirce-Sandner of Optum, and was funded by Merck \& Co., Inc.

\section{Disclosure}

Ankita Modi, and Vasilisa Sazonov are employees of Merck \& Co., Inc., and Jingbo Yu was an employee at the time of the study and during manuscript development. Susan $\mathrm{K}$ Brenneman is an employee of Optum, Eden Prairie, MN, and served as a paid consultant to Merck for the conduct of this study and manuscript development. The authors report no other conflicts of interest in this work.

\section{References}

1. Burge R, Dawson-Hughes B, Solomon DH, Wong JB, King A, Tosteson A. Incidence and economic burden of osteoporosis-related fractures in the United States, 2005-2025. J Bone Miner Res. 2007;22(3):465-475.

2. Adachi JD, Adami S, Gehlbach S, et al; GLOW Investigators. Impact of prevalent fractures on quality of life: baseline results from the global longitudinal study of osteoporosis in women. Mayo Clin Proc. 2010; 85(9):806-813.

3. Roux C, Wyman A, Hooven FH, et al; GLOW Investigators. Burden of non-hip, non-vertebral fractures on quality of life in postmenopausal women: the Global Longitudinal study of Osteoporosis in Women (GLOW). Osteoporos Int. 2012;23(12):2863-2871.

4. Abrahamsen B, van Staa T, Ariely R, Olson M, Cooper C. Excess mortality following hip fracture: a systematic epidemiological review. Osteoporos Int. 2009;20(10):1633-1650.

5. National Osteoporosis Foundation. Clinician's Guide to Prevention and Treatment of Osteoporosis. 2014 Issue, Version 1. Washington, DC. Available from: http://nof.org/files/nof/public/content/file/2791/ upload/919.pdf. Accessed January 12, 2015. 
6. Dawson-Hughes B, Looker AC, Tosteson AN, Johansson H, Kanis JA, Melton LJ 3rd. The potential impact of the National Osteoporosis Foundation guidance on treatment eligibility in the USA: an update in NHANES 2005-2008. Osteoporos Int. 2012;23(3):811-820.

7. Asche C, Nelson R, McAdam-Marx C, Jhaveri M, Ye X. Predictors of oral bisphosphonate prescriptions in post-menopausal women with osteoporosis in a real-world setting in the USA. Osteoporos Int. 2010; 21(8):1427-1436.

8. Díez-Pérez A, Hooven FH, Adachi JD, et al. Regional differences in treatment for osteoporosis. The Global Longitudinal Study of Osteoporosis in Women (GLOW). Bone. 2011;49(3):493-498.

9. Guggina P, Flahive J, Hooven FH, et al; GLOW Investigators. Characteristics associated with anti-osteoporosis medication use: data from the Global Longitudinal Study of Osteoporosis in Women (GLOW) USA cohort. Bone. 2012;51(6):975-980.

10. Siris ES, Modi A, Tang J, Gandhi S, Sen S. Substantial under-treatment among women diagnosed with osteoporosis in a US managed-care population: a retrospective analysis. Curr Med Res Opin. 2014; 30(1):123-130.

11. McHorney CA, Spain CV. Frequency of and reasons for medication non-fulfillment and non-persistence among American adults with chronic disease in 2008. Health Expect. 2011;14(3):307-320.

12. Reynolds K, Muntner P, Cheetham TC, et al. Primary non-adherence to bisphosphonates in an integrated healthcare setting. Osteoporos Int. 2013;24(9):2509-2517.

13. Yood RA, Mazor KM, Andrade SE, Emani S, Chan W, Kahler KH. Patient decision to initiate therapy for osteoporosis: the influence of knowledge and beliefs. J Gen Intern Med. 2008;23(11):1815-1821.

14. Barrett-Connor E, Wade SW, Do TP, et al. Treatment satisfaction and persistence among postmenopausal women on osteoporosis medications: 12-month results from POSSIBLE US. Osteoporos Int. 2012;23(2):733-741.
15. Quan H, Sundararajan V, Halfon $\mathrm{P}$, et al. Coding algorithms for defining comorbidities in ICD-9-CM and ICD-10 administrative data. Med Care. 2005;43(11):1130-1139.

16. US Department of Labor. Bureau of Labor Statistics. [webpage on Internet]. Consumer Price Index - Chained Consumer Price Index. Available from: http://data.bls.gov/cgi-bin/surveymost. Accessed January 12, 2015.

17. Meadows ES, Mitchell BD, Bolge SC, Johnston JA, Col NF. Factors associated with treatment of women with osteoporosis or osteopenia from a national survey. BMC Womens Health. 2012;12:1.

18. ScovilleEA, Ponce de Leon Lovaton P, Shah ND, Pencille LJ, Montori VM. Why do women reject bisphosphonates for osteoporosis? A videographic study. PLoS One. 2011;6(4):e18468.

19. Hiligsmann M, Dellaert BG, Dirksen CD, et al. Patients' preferences for osteoporosis drug treatment: a discrete-choice experiment. Arthritis Res Ther. 2014;16(1):R36.

20. Mazor KM, Velten S, Andrade SE, Yood RA. Older women's views about prescription osteoporosis medication: a cross-sectional, qualitative study. Drugs Aging. 2010;27(12):999-1008.

21. Sale JE, Gignac MA, Hawker G, et al. Decision to take osteoporosis medication in patients who have had a fracture and are 'high' risk for future fracture: a qualitative study. BMC Musculoskelet Disord. 2011; 12:92.

22. Montori VM, Shah ND, Pencille LJ, et al. Use of a decision aid to improve treatment decisions in osteoporosis: the osteoporosis choice randomized trial. Am J Med. 2011;124(6):549-556.
Patient Preference and Adherence

\section{Publish your work in this journal}

Patient Preference and Adherence is an international, peer-reviewed, open access journal that focuses on the growing importance of patient preference and adherence throughout the therapeutic continuum. Patient satisfaction, acceptability, quality of life, compliance, persistence and their role in developing new therapeutic modalities and compounds to optimize

\section{Dovepress}

clinical outcomes for existing disease states are major areas of interest for the journal. This journal has been accepted for indexing on PubMed Central. The manuscript management system is completely online and includes a very quick and fair peer-review system, which is all easy to use. Visit http://www. dovepress.com/testimonials.php to read real quotes from published authors. 